\title{
Emergency coronary artery surgery after refractory cardiac arrest: a single centre experience
}

J G Powney, R S Bonser, S Lentini

\begin{abstract}
Objective-To determine the incidence and outcome of refractory cardiac arrest necessitating emergency coronary artery bypass grafting.

Design-Retrospective survey of cardiac catheterisation and surgical records. Setting-The London Chest Hospital.

Patients-All patients requiring emergency coronary artery bypass grafting after cardiovascular collapse in the catheterisation suite between January 1984 and December 1989.

Main outcome measures-Incidence of refractory cardiac arrest in the study group and perioperative mortality.

Results-Thirteen of 8675 patients undergoing coronary arteriography or angioplasty had refractory cardiac arrests. Five patients died, but the remainder survived to be discharged from hospital without serious morbidity.

Conclusion-Without immediate surgical intervention the mortality for these 13 patients would have been $100 \%$.
\end{abstract}

Emergency myocardial revascularisation is occasionally required after coronary angioplasty or arteriography. Angioplasty is the higher risk procedure and 1 to $6 \%$ of patients will require emergency surgery. ${ }^{1}$ Of these, up to one third will present to the surgical team with severe left ventricular dysfunction and cardiogenic shock. ${ }^{2}$ Two thirds of patients who undergo acute coronary occlusion will require bypass surgery. ${ }^{3}$ Coronry arteriography may also be complicated by coronary artery dissection or occlusion and a recent study reports an incidence of about $0.3 \%$ and mortality of $0 \cdot 2 \% .{ }^{4}$ There is a high probability that all patients with cardiogenic shock secondary to unsuccessful balloon dilatation develop some myocardial necrosis. The incidence of nonfatal new $Q$ wave myocardial infarction in patients undergoing emergency surgery after failed coronary angioplasty is 25 to $40 \%{ }^{5-7}$ The mortality for revascularisation in these cases is also high and previous reports have indicated a high operative mortality in those patients who have cardiac arrest at the time of operation. ${ }^{89}$ This survey details the results of emergency revascularisation in patients with refractory cardiac arrest during or immediately after coronary arteriography or angioplasty at a single centre.

\section{Patients and methods}

A full, retrospective survey of cardiac catheterisation and surgical records for the six year period, January 1984 to December 1989, was undertaken. The incidence of refractory cardiac arrest, which complicated coronary arteriography or angioplasty and necessitated emergency surgery, was found. Refractory cardiac arrest was defined as cardiac arrest unresponsive to conventional treatment including cardiotonic drugs, external cardiac massage, and repeated defibrillation, with resuscitative efforts continued up to median sternotomy, followed by internal cardiac massage. This group did not include complications of valvar disease investigation or postinfarction ventricular rupture. We excluded patients with transient rhythm or haemodynamic disturbances who did not develop refractory cardiac arrest requiring full resuscitation during transfer to the operating theatre. These have been reported elsewhere.

All angioplasty patients had adequate vascular access in the form of femoral venous and arterial cannlas before cardiac arrest. Patients undergoing diagnostic arteriography had only rudimentary access via the brachial arteriotomy and a peripheral venous cannula. During the course of resuscitation, central (jugular) venous access was secured in seven patients.

Cardiopulmonary bypass in this critical situation was carried out as follows in: a member of staff wearing a sterile gown performed external cardiac massage through a betadine soaked swab while preparation and draping proceeded around him. Fully scrubbed and gowned surgeons then continued the massage, which was momentarily interrupted for scalpel incision down to the sternum. After rapid sternotomy, insertion of a chest spreader, and opening of the pericardium (manoeuvres which take seconds), internal cardiac massage was performed by one surgeon, while another inserted cannulation purse strings. Aortic and right atrial cannulas were then inserted with prompt initiation of bypass.

When necessary, a monitoring needle was inserted in the aorta for the adjustment of perfusion pressure and flow after initiation of cardiopulmonary bypass. Most of our patients were operated on using the technique of intermittent ischaemic arrest at $32^{\circ} \mathrm{C}$ rather than cold cardioplegic arrest.

At the time of the initial cardiac arrest, all 
Table 1 Preoperative and angioplasty/angiography data

\begin{tabular}{|c|c|c|c|c|}
\hline Patient & Age/sex & Presentation & $\begin{array}{l}\text { Site of } \\
\text { disease }\end{array}$ & $\begin{array}{l}\text { PTCA } \\
\text { artery }\end{array}$ \\
\hline $\begin{array}{r}1 \\
2 \\
3 \\
4 \\
5 \\
6 \\
7 \\
8 \\
9 \\
10 \\
11 \\
12 \\
13\end{array}$ & 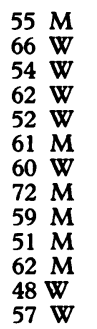 & $\begin{array}{l}\text { UA } \\
\text { UA } \\
\text { SA } \\
\text { UA } \\
\text { UA } \\
\text { SA } \\
\text { UA } \\
\text { UA } \\
\text { UA } \\
\text { PIA } \\
\text { SA } \\
\text { SA } \\
\text { PIA }\end{array}$ & $\begin{array}{l}\text { RCA/LAD } \\
\text { LAD/Cx } \\
\text { RCA/LAD/Cx } \\
\text { RCA/LAD } \\
\text { LAD/Cx } \\
\text { RCA/LAD } \\
\text { LAD } \\
\text { RCA/LAD/Cx } \\
\text { LAD/Cx } \\
\text { LAD/Cx } \\
\text { LMS/occ RCA } \\
\text { LMS/RCA } \\
\text { RCA/LAD/Cx }\end{array}$ & $\begin{array}{l}\text { RCA } \\
\text { LAD } \\
\text { LAD/Cx injury } \\
\text { RCA/LAD } \\
\text { LAD } \\
\text { LAD } \\
\text { LAD/Cx injury } \\
\text { LAD/Cx injury } \\
\text { LAD } \\
\text { LAD/Cx injury } \\
\text { N/A } \\
\text { N/A } \\
\text { N/A }\end{array}$ \\
\hline
\end{tabular}

PTCA, percutaneous transluminal coronary angioplasty; RCA, right coronary artery; LAD, left anterior descending artery; $\mathrm{Cx}$, circumflex artery; LMS, left main stem; Occ, occluded; N/A, not applicable; PIA, post infarct angina; SA, stable angina; UA, unstable angina.

patients were intubated and ventilated with $100 \%$ oxygen. No inhalational anaesthetic agents were administered. Despite the moribund condition of these patients, intravenous anaesthetic drugs, if only a small dose of benzodiazepine with pancuronium, were rarely withheld before sternotomy. Once on cardiopulmonary bypass, the routine opiate benzodiazepine relaxant sequence normally used was given with only minor modifications in dosage.

Heparin, ( $3 \mathrm{mg} / \mathrm{kg}$ ) was given at the earliest opportunity bearing in mind the slow circulation time that is inevitable with intermittent cardiac massage. All angioplasty patients had also received $100 \mathrm{mg}$ of heparin at the outset of the procedure.

Various treatments were directed towards preservation of vital organs. These included $10 \mathrm{~g}$ mannitol and $2 \mathrm{~g}$ methylprednisolone or $20 \mathrm{mg}$ dexamethasone for putative cerebral protection, glyceryl trinitrate infusion to facilitate myocardial preservation, and for renal protection, dopamine infusion and diuretics. Barbiturates were not used at all in either anaesthetic or cerebrally protective doses.

\section{Results}

Tables 1 and 2 show the preoperative and perioperative details of the 13 patients. Diagnostic coronary arteriography was performed in 7635 patients at the London Chest Hospital in the study period 1984 to 1989 . Eight patients $(0 \cdot 1 \%)$ were referred for urgent surgery from

Table 2 Perioperative details and outcome

\begin{tabular}{lllllll}
\hline Patient & Rhythm & $\begin{array}{c}\text { Duration } \\
\text { of CPR } \\
\text { (min) }\end{array}$ & Operation & $\begin{array}{l}\text { Operative } \\
\text { technique }\end{array}$ & $\begin{array}{l}\text { Days in } \\
\text { ICU }\end{array}$ & Outcome \\
\hline 1 & VF & 45 & VG $\times 2$ & Int fib & 2 & Survived \\
2 & VF/asystole & 45 & VG $\times 2$ & Int fib & N/A & Died in OT \\
3 & Bradycardia/VF & 60 & VG $\times 2$ & CPL & N/A & Died in OT \\
4 & $2: 1$ AVB/VF & 30 & VG $\times 2$ & CPL & 7 & Died MSOF \\
5 & VF & 30 & VG $\times 2$ & Int fib & 2 & Survived \\
6 & VF & 40 & VG $\times 2$ & Int fib & N/A & Died in OT \\
7 & VF & $<30$ & VG $\times 2$ & Int fib & 2 & Survived \\
8 & VF & 40 & VG $\times 4$ & Int fib & 6 & Survived \\
9 & VF & 45 & VG $\times 2$ & Int fib & N/A & Died in OT \\
10 & VF & $<30$ & VG $\times 2$ & Int fib & 4 & Survived \\
11 & VF & 45 & VG $\times 3$ & Int fib & 4 & Survived \\
12 & Asystole & 30 & VG $\times 3$ & CPL & 4 & Survived \\
13 & VF/asystole & 30 & VG $\times 3$ & CPL & 3 & Survived \\
\hline
\end{tabular}

CPR, cardiopulmonary resuscitation; VF, ventricular fibrillation; AVB, atrioventricular block VG, vein graft; Int fib, intermittent fibrillation; CPL, cardioplegia; MSOF, multisystem organ failure; N/A, not applicable; OT, operating theatre. the catheter laboratory because of haemodynamic instability or severe myocardial ischaemia. Of these eight patients, three $(0.03 \%)$ had cardiac arrests requiring full resuscitation including external cardiac massage during transfer to theatre for surgical revascularisation. All three survived and made a good functional recovery, although two had perioperative myocardial infarction on electrocardiographic criteria.

During the same period, 1040 patients underwent percutaneous coronary angioplasty. Sixty seven $(6.4 \%)$ of these patients were referred for urgent surgery. The reasons for surgical referral included coronary artery dissection and occlusion, persistent chest pain, or ST segment changes despite apparently successful angioplasty, and failure to pass a guidewire or angioplasty catheter across a critical lesion associated with pain and electrocardiographic changes. In 10 patients $(1 \%)$ immediate surgery was required for refractory cardiac arrest with complete circulatory collapse. The maximum time to cardiopulmonary bypass was 45 minutes. Four patients could not be resuscitated despite rapid surgical intervention and revascularisation, and maximum inotropic support, and died in the operating theatre. One patient died of low cardiac output and multi system organ failure seven days after operation. The mortality for the complication of refractory cardiac arrest after angioplasty was therefore $50 \%$.

The survivors for both groups (61\%) had remarkably uncomplicated postoperative courses in the light of their history. One patient (no 5) came off cardiopulmonary bypass with no support at all and was discharged from intensive care the next day. Two patients required inotropic support and four also had assistance from surgically introduced intraaortic balloon pumps. Six patients were discharged from intensive care by day 3 . One remained intubated to day 4 because of a recurrent pneumothorax, and another with a pre-operative history of chronic bronchitis remained in intensive care for six days. Functional recovery was excellent: there was no evidence of cerebral, pulmonary or renal deficit in any of the long-term survivors and their median post-operative hospital stay was 15 days (range 8-30). In two patients, hospital discharge was delayed by superficial infection of an intra-aortic balloon entry site reflecting the less than ideal preparation of patients before surgery. There had been no late deaths at one year follow up.

\section{Discussion}

The provision of surgical cover for invasive cardiological diagnostic and therapeutic procedures has been the subject of much debate. ${ }^{4111}$ This study, while raising issues that have been discussed previously, throws some light on the problem of identifying what determines the outcome of those patients who have the very worst angiographic complication-refractory cardiac arrest. Stewart et al have indicated that it is extremely difficult to 
prove the assumption that the temporal and geographical availability of surgical facilities affects the prognosis of patients referred for emergency surgery. ${ }^{4}$ This difficulty must be all the greater when the patients in question include those with some spontaneous cardiac output who can, albeit precariously, be supported during any delay. In this report, therefore, we have considered in detail only those patients with refractory cardiac arrest as we believe that survival would not have been possible without recourse to immediate surgery which allowed the institution of cardiopulmonary bypass and steps towards reperfusion within an hour of arrest. Our results show that $61 \%$ of such patients survived this ultimate of complications with excellent functional recovery after comparatively short stays in intensive care and hospital. We know of no other data from the United Kingdom to suggest that similar patients would achieve a similar outcome if transferred to another hospital.

Whereas it is possible that all our patients would have survived if transferred elsewhere, we believe that a salvage rate of this order is only likely to be achieved if invasive cardiological procedures are performed in the same place as cardiac surgery facilities are available for rapid intervention should refractory cardiac arrest occur. This belief is in accordance with that of other workers. ${ }^{4}$ Whether this mortality can be offset by the development of local diagnostic coronary angiographic services saving lives by earlier diagnosis and referral for surgical intervention of prognostically important coronary disease is not known, but has been previously considered. ${ }^{1012}$ Certainly, increased availability of diagnostic procedures will not influence mortality unless treatment facilities expand in parallel.

On site surgical cover for percutaneous transluminal angioplasty has been recommended in American practice, ${ }^{13}$ but formal guidelines have not been issued in the United Kingdom. Other workers have suggested that coronary angioplasty can be safely performed at centres distant to surgical facilities and quote considerable and equivalent times to revascularisation with both on site and distant referral. ${ }^{10}$ The delay is identified as nonavailability of a cardiac operating theatre.

At the London Chest Hospital there is no special provision for an empty theatre on stand by, but angioplasty procedures have generally been timed to occur when the first surgical cases are nearing completion. This overlapping practice contributes to a reduction in delay should surgical intervention be necessary. Also, it has been accepted that other sites-for example, the catheter laboratory or anaesthetic room-can be used as an operating theatre in desperate circumstances. We have found surgery in the catheter laboratory less than ideal. The risk of transfer and increased delay for patients undergoing external cardiac massage is likely to be offset by the benefits of surgeons, anaesthetists, and support staff operating in a familiar and properly equipped environment.

The problem of speed of access to surgical facilities is likely to be the most decisive factor influencing outcome, but there are other con- siderations worthy of discussion in the future. These include catheter laboratory techniques, the skill and seniority of the cardiologist, the speed of recognition of a serious problem, and the initial resuscitation efforts with early involvement of anaesthetists and surgeons of adequate seniority. It is not our view or experience that failure to establish a rhythm and cardiac output makes revascularisation pointless.

Our method of establishing cardiopulmonary bypass was always by direct central cannulation following sternotomy. Percutaneous femoral cannulation kits were not available to our unit, and we considered that to try to isolate, control, and tape the femoral vessels, and insert the femoral cannulas, with the patient undergoing external cardiac massage, was time consuming and difficult. Appropriate coordination of personnel to continue ventilation and external cardiac massage during preparation and draping allowed prompt sternotomy and completion of cardiopulmonary bypass. More peripheral manoeuvres, although suitable in some centres, would have led to a delay of revascularisation in our practice.

In conclusion, this study shows that significant surgical salvage rates can be achieved by prompt intervention in this extremely high risk subgroup of patients. Centres that undertake invasive cardiology will have a complication rate that includes refractory cardiac arrest, an event that is unpredictable. Our results show that, in this event, a $61 \%$ survival rate is achievable and therefore we argue strongly that cardiological and surgical facilities should be close.

We thank the consultants in the departments of anaesthesia, surgery, and cardiology at the London Chest Hospital for help and advice.

1 Cowley MJ, Dorros G, Kelsey SF, Raden MV, Detre KM emergency coronary bypass surgery after coronary angioplasty: the National Heart, Lung, and Blood Institute's percutaneous transluminal angioplasty registry experience. Am J Cardiol 1984;53 (suppl):22-6.

2 Bolooki H. Emergency cardiac procedures in patients in cardiogenic shock due to complications of coronary artery disease. Circulation 1989;79 (suppl I):137-48.

3 King SB III. Prediction of acute closure in percutaneous transluminal coronary angioplasty. Circulation 1990;81: 5-7.

4 Stewart JT, Gray HH, Ward DE, Pumphrey W, Redwood DR, Parker DJ. Major complications of coronary arteriography: the place of cardiac surgery. Br Heart $J$ 1990;63:74-7.

5 Spencer FC. A critique of emergency and urgent operations for complications of coronary artery disease. Circulation for complications of cor

6 Talley JD, Weintraub WS, Anderson HV, et al. Late clinical outcome of coronary bypass surgery after failed electiv PTCA [abstract]. Circulation 1987;76 (suppl IV):352.

7 Ullyot DJ. Surgical standby for percutaneous coronary angioplasty. Circulation 1987;76 (suppl III):149-52.

8 Golding LAR, Loop FD, Hollman JL, et al. Early results of emergency after coronary angioplasty. Circulation 1986 74: (suppl III):26.

9 Reul GJ, Cooley DA, Hallman GL, et al. Coronary artery bypass for unsuccessful percutaneous transluminal coronary angioplasty, $J$ Thorac Cardiovasc Surg 1984;88: ary ang -94 .

10 Richardson SG, Morton P, Murtagh JG, O'Keeffe DB, Murphy P, Scott ME. Management of acute coronary occlusion during percutaneous transluminal coronary angioplasty: experience of complications in a hospital without on site facilities for cardiac surgery. $\mathrm{Br}$ Med $J$ 1990;300:355-8.

11 Bayliss J, Shakespeare C, Lincoln C, Sutton R. Does invasive cardiology require the presence of surgery? invasive cardiology require the
[abstract] $B r$ Heart $J$ 1987;57:79.

12 Mills $P$. Should coronary angiography be performed in district hospitals? Br Heart J 1990;63:73.

13 Ryan TJ, Faxon DP, Gunnar RM, et al. Guidelines for percutaneous transluminal coronary angioplasty. Circulation 1988;2:486-502. 